\title{
PERCEPÇÕES E SENTIMENTOS DE ALUNOS DO ENSINO MÉDIO EM RELAÇÃO À MATEMÁTICA
}

\section{PERCEPTIONS AND FEELINGS OF HIGH SCHOOL STUDENTS \\ REGARDING MATHEMATICS}

\author{
Gabriel de Oliveira Soares ${ }^{1}$ \\ Universidade Franciscana (UFN) \\ Andressa Franco Vargas ${ }^{2}$ \\ Universidade Franciscana (UFN) \\ José Carlos Pinto Leivas ${ }^{3}$ \\ Universidade Franciscana (UFN)
}

\section{Resumo}

Levando em consideração a influência do domínio afetivo no aprender e, em especial, no aprender matemática (CHACÓN, 2003), desenvolveu-se esse estudo que teve por objetivo investigar percepções e sentimentos de alunos do Ensino Médio em relação à matemática expressas por uma turma desse nível de escolaridade de uma instituição pública de um município da região central do estado do Rio Grande do Sul. Para tal, aplicou-se um questionário estruturado, composto por quatro questões, a vinte e oito estudantes concluintes dessa etapa da Educação Básica. As questões propostas relacionaram um possível caráter excludente da disciplina, as experiências pessoais a partir de metáforas e os sentimentos relativos ao conteúdo baseado em um desenho. Após a coleta dos dados, esses foram analisados tendo em vista uma abordagem interpretativodescritiva, na qual foram compostas categorias à posteriori. Os resultados evidenciaram que saber matemática, na percepção dos estudantes, se relaciona principalmente às aplicações de conceitos matemáticos em atividades cotidianas. Mostraram também que em se tratando de experiências passadas, os alunos evidenciaram metáforas bastante negativas à essa disciplina, comparando-a majoritariamente a animais com características de causarem medo ou desconforto. Por fim, ao serem solicitados a desenharem como se sentiam em relação ao componente curricular em questão, os alunos apresentaram imagens com sentimentos ruins, em sua maioria, destacando-se as intersecções entre visões boas e más dessa disciplina. Dessa forma, conclui-se que, ao conhecer essas percepções e sentimentos em relação à matemática dos estudantes, os professores podem elaborar estratégias buscando romper com uma visão negativa perante a disciplina, além de buscar melhorar a aprendizagem dos mesmos.

Palavras-chave: Ensino de Matemática; Ensino Médio; Percepções e Sentimentos.

\footnotetext{
${ }^{1}$ gsoares8@outlook.com

2 andressavargas1@yahoo.com.br

3 leivasjc@ufn.edu.br
} 


\begin{abstract}
Taking into account the influence of the affective domain in learning and, especially, in learning mathematics (CHACÓN, 2003), this study was developed with the objective of investigating the perceptions and feelings of high school students in relation to mathematics expressed by a class of this level of schooling of a public institution in a municipality in the central region of the state of Rio Grande do Sul. To this end, a structured questionnaire, consisting of four questions, was applied to twenty-eight students completing this stage of basic education. The proposed questions related to a possible exclusionary character of the discipline, personal experiences based on metaphors and feelings related to content based on a drawing. After collecting the data, these were analyzed with a view to an interpretive-descriptive approach, in which categories were composed at posteriori. The results showed that knowing mathematics, in the students' perception, is mainly related to the application of mathematical concepts in daily activities. They also showed that when dealing with past experiences, the students evidenced metaphors very negative relationships to this discipline, comparing it mostly to animals with characteristics of causing fear or discomfort. Finally, when asked to draw how they felt about the curricular component in question, the students presented images with mostly bad feelings, highlighting the intersections between good and bad views of this discipline. Thus, it is concluded that, by knowing these perceptions and feelings in relation to students' mathematics, teachers can develop strategies seeking to break with a negative view of the discipline, in addition to seeking to improve their learning.
\end{abstract}

Keywords: Mathematics teaching; High school; Perceptions and Feelings.

\title{
1. Introdução
}

O ensino da matemática na Educação Básica possui diversas funções sociais: serve de base ao desenvolvimento de uma cultura científica e tecnológica; a disciplina tem destaque em concursos e em seleções de ingresso em cursos superiores, como no Exame Nacional do Ensino Médio; e serve como uma forma de promover "o desenvolvimento das crianças e dos jovens, estimulando uma maneira de pensar importante para a vida social e para o exercício da cidadania” (PONTE, 2002, p. 13).

Entretanto, esbarra-se em um grande problema no que tange ao ensino dessa disciplina: a precarização da Educação Básica, que leva a diversos problemas de sua aprendizagem. Sobre esses problemas, pode-se citar estudos como os de Lorenzato (2010), ao abordar as questões relacionadas ao ensino da matemática ainda ser mecanizado e feito através de algoritmos; Silveira (2011), ao apontar que a disciplina é excludente, enfatiza que alguns estudantes têm a visão de que saber matemática é apenas para algumas pessoas; e Pacheco e Andreis (2018), ao relacionarem as principais dificuldades encontradas em seu estudo, como sendo a falta de compreensão e 
interpretação de determinados conteúdos, o esquecimento daqueles trabalhados anteriormente, a dificuldade de concentração e a forma com que o professor apresenta o conteúdo.

Nesse sentido, pesquisas envolvendo a compreensão dessas dificuldades que podem influenciar na aprendizagem em matemática se fazem essenciais, levando em consideração a relevância dessa disciplina para uma formação integral de estudantes, nos mais diferentes níveis de ensino. Sobre esse tópico, Sanchez (2014, p. 174-175) categorizou as dificuldades em 5 grandes grupos, sendo um deles, "dificuldades quanto às crenças, às atitudes, às expectativas e a fatores emocionais acerca da matemática”.

Essa disciplina pode carregar fatores emocionais que levem o aluno a se sentir incapacitado ao resolver problemas, ou a compreender soluções que a envolvem. Dessa forma, retoma-se o apontado por Silveira (2011), ao criar uma ideia de que a matemática seria excludente.

Estudos acerca das crenças e concepções de professores sobre matemática já vêm sendo realizados faz algum tempo, como os de Cury (1999); Nacarato, Passos e Carvalho (2004); Garnica (2008). Entretanto, esses estudos têm se voltado a pesquisas com professores em formação inicial ou continuada, e crê-se que investigações com alunos também sejam importantes, afinal, eles também são atores que participam do processo de aprendizagem no âmbito escolar e a sua aprendizagem é um dos principais objetivos da educação, se não o mais importante.

Dessa forma, esse estudo tem por objetivo investigar percepções e sentimentos de alunos do Ensino Médio em relação à matemática expressas por uma turma desse nível de escolaridade de uma instituição pública de ensino de um município da região central do estado do Rio Grande do Sul. Ao investigá-las, acredita-se que seja possível identificar como o trabalho com a matemática em sala de aula pode ser feito, com vistas, principalmente, a traçar caminhos metodológicos para a prática docente diária.

\section{O domínio afetivo influenciando no aprender matemática}

Aprender, em um sentido geral, demanda uma pré-disposição de quem aprende. Entretanto, em se tratando das condições do aprender, diversos fatores do domínio afetivo podem dificultá-lo, podendo-se destacar as ideias pré-concebidas sobre conteúdos, disciplinas e dificuldades, sentimentos e crenças, entre outros. 
Teorias de aprendizagem em matemática, como a Teoria dos Três Mundos da Matemática, proposta por Tall (2013), vêm elencando o papel das emoções ao aprender essa disciplina. Outros autores, como Fonseca (1999) e Chacón (2003), destacam que as crenças, atitudes e emoções dos estudantes perante esse componente curricular acabam por regular o que o estudante aprende, tendo em vista,

[...] por exemplo, se o aluno que entende a matemática como cálculo tiver um reforço dessa ideia durante a escola básica, no futuro ele apresentará resistência em realizar tarefas que exijam pensar, manifestando medo, desânimo e vontade de abandoná-las, com pouca efetividade na abordagem e com grande dificuldade (CHACÓN, 2003, p. 24).

Além desses, Pienda et al. (2005) apontam que a influência do domínio afetivo é processo que pode afetar, tanto no baixo rendimento e no insucesso dos alunos ao desenvolverem as tarefas de matemática, quanto no seu sucesso.

Assim, é papel do professor trabalhar com essas crenças, sentimentos e atitudes buscando melhorá-los, tendo em vista que,

\begin{abstract}
ao aprender matemática, o estudante recebe estímulos contínuos associados a ela - problemas, atuações do professor, mensagens sociais, etc. - que geram nele uma certa tensão. Perante este estímulo reage emocionalmente de forma positiva ou negativa. Essa reação está condicionada pelas suas crenças sobre si mesmo e sobre a matemática. Se o indivíduo se depara com situações similares repetidamente, produzindo o mesmo tipo de reações afetivas, então a indução da reação emocional (satisfação, frustração, etc.) pode tornar-se mecânica e "consolidar-se" em atitudes. Essas atitudes e emoções influenciam as crenças e contribuem para sua formação (CHACÓN, 2003, p.23).
\end{abstract}

Essa mudança deve se dar de forma contínua, pois os sentimentos e crenças não mudam de uma hora para outra. Possibilidades diversas de trabalho em sala de aula podem ser utilizadas nesse sentido, mas deve-se optar, principalmente, por oportunizar vivências agradáveis para os estudantes, com a utilização de jogos, brincadeiras, materiais didáticos, entre outros. Ou seja, explorar metodologias que fujam do modo tradicional de ensinar.

Ao fazer isso, o professor propõe mudanças em como os alunos podem aprender, melhorando o trabalho em sala de aula, considerando que é "importante propor intervenções que ajudem os alunos a saírem do estado de bloqueio diante da atividade matemática” (CHACÓN, 2003, p. 25).

Outros aspectos que merecem atenção nesse contexto são os erros e a avaliação. Sobre esses, Macedo (1994) traz que muitos sentimentos podem emergir em decorrência 
do rigor e da severidade com que a sociedade, de modo geral, encara tal comportamento. Logo, o professor deve atentar-se para passar uma postura positiva em relação a eles, concebendo os erros como oportunidades de melhorar a aprendizagem e a avaliação como um modelo de conhecer e aprofundar conhecimentos.

\section{Aspectos metodológicos}

Como o objetivo desta pesquisa é compreender as crenças e concepções de matemática de um grupo de estudantes do Ensino Médio, entende-se que há a necessidade de investigar o que eles pensam e sentem em relação à essa disciplina.

Dessa forma, optou-se por um estudo qualitativo para o desenvolvimento do estudo, levando em conta que, segundo Lüdke e André (1986), esse tipo de abordagem compreende a obtenção de dados descritivos, levantados diretamente pelo pesquisador no campo, dando ênfase no processo e preocupando-se em retratar o entendimento dos participantes.

Dessa forma, a fim de atender ao objetivo da pesquisa, foi aplicado um questionário a vinte e oito estudantes. A amostra foi selecionada por conveniência, sendo os alunos convidados a participarem do estudo em questão.

O questionário proposto aos estudantes foi composto por quatro questões, baseadas nas perguntas elaboradas por Ferreira (2009) e Silva e Santos-Wagner (2013). O Quadro 1 sintetiza tais perguntas.

Quadro 1 - Questões propostas aos estudantes

1. Para você, o que significa saber matemática? Por quê?

2. Se a matemática fosse um animal, qual ela seria? Por quê?

3.Qual animal a matemática nunca seria? Por quê?

4. Faça um desenho que expresse seu pensamento e sentimento em relação à matemática.

Fonte: baseadas em Ferreira (2009) e Silva; Santos-Wagner (2013).

As questões foram propostas na busca de elucidar alguns aspectos específicos. Por exemplo, na primeira questão foi descobrir se os alunos têm uma visão de que saber matemática é para poucas pessoas, ou seja, se a disciplina tem um caráter excludente, em suas concepções.

Já as duas questões seguintes exploram como os estudantes associam suas experiências com a disciplina em percepções sobre animais, fazendo um paralelo entre a 
matemática e os animais. Esse paralelo é feito em relação às imagens sociais que os animais representam: por exemplo, uma cobra, geralmente causa medo, enquanto animais como coelhos podem ser tidos como mais tranquilos. Assim, ao fazer esse comparativo, têm-se um olhar sobre o caráter afetivo nas experiências passadas dos alunos. Esse, é detalhado em trabalhos como os de Ferreira (2009), e se baseiam principalmente nas ideias de Chapman (2006).

A última questão objetiva compreender fatores emocionais relacionados à aprendizagem da disciplina. Esses foram apresentados por Sanchez (2014) como um dos obstáculos de aprendizagem em matemática e corroboram com a ideia dos estudos de Belardi Neto e Martins (2015).

Para a análise dos dados, optou-se por uma análise interpretativa, na qual criaramse categorias após a exploração dos dados, buscando contemplar o objetivo do estudo. Os estudantes foram indicados por A1, A2,.., A28, evitando assim sua identificação. Para ilustrar os resultados, optou-se por digitar a resposta dos estudantes, conservando a linguagem da forma como foi enunciada pelo aluno. Em outros casos, foi digitalizada para ser fiel à figura desenhada pelo respondente.

\section{Apresentação e análise dos dados}

Para uma melhor organização e compreensão dos dados desta pesquisa, optou-se por analisar as questões separadamente, de modo que as respostas de cada uma assumissem categorias distintas com o intuito de priorizar a autenticidade e as diferenças entre elas.

A primeira questão trata da significação dada pelo aluno quando ele pensa no "saber matemático", gerando um repertório de respostas bem amplo e variado. Para alguns, saber matemática significa entender um pouco da vida, aprender mais sobre o mundo e desenvolver a habilidade de resolver problemas quase sempre complicados. Sendo assim, o Quadro 2 sintetiza o número de respostas e as categorias admitidas à primeira questão. 
Quadro 2 - Categorias correspondentes à primeira questão

\begin{tabular}{|c|c|}
\hline \multicolumn{2}{|c|}{ Questão 1: Para você, o que significa saber matemática? Por quê? } \\
\hline Categorias & $\begin{array}{c}\text { Número de } \\
\text { Respostas }\end{array}$ \\
\hline Significa saber operar matematicamente (adição, subtração, \\
multiplicação e divisão) & 3 respostas \\
\hline Significa saber resolver problemas & 4 respostas \\
\hline Significa ter conhecimentos difíceis/específicos & 6 respostas \\
\hline Significa relacionar a matemática com o cotidiano & 15 respostas \\
\hline
\end{tabular}

Fonte: dados da pesquisa.

As respostas englobadas na primeira categoria enfatizaram questões sobre o saber matemática consistir em conhecer noções básicas relativas à adição, subtração, multiplicação e divisão de números pois, para os alunos, estes seriam os critérios básicos para a construção do saber matemática. A Figura 1 traz a resposta do aluno A4, que evidencia o conteúdo das respostas dispostas nesta categoria.

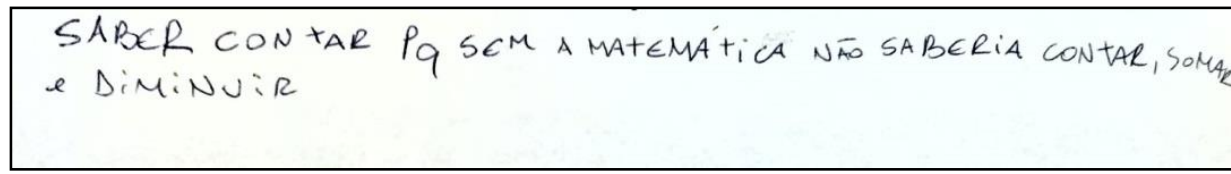

Figura 1 - Resposta do aluno A4 correspondente à primeira questão Fonte: dados da pesquisa.

Observa-se, na resposta do aluno, as expressões para as operações de adição e subtração: somar e diminuir, algo comum para os primeiros segmentos do ensino, entretanto já deveriam estar mais bem formalizadas ao final do Ensino Médio.

A segunda categoria formada refere-se ao saber resolver problemas, sendo eles difíceis ou não e que estejam ligados à interpretação e ao desenvolvimento das habilidades, contemplando atividades do cotidiano e da sala de aula. Pode-se ressaltar que, em muitas respostas, foi observado o fato de que saber matemática pode influenciar na capacidade de resolver problemas do cotidiano de maneira prática e racional e, consequentemente, auxiliar em atividades corriqueiras.

A terceira categoria construída destaca os conhecimentos "difíceis" e "específicos". Nessa, as respostas consistiram em frases enaltecendo o conhecimento 
necessário para construir o saber matemático e a visão dos alunos sobre estes conhecimentos, ficando evidenciada a ideia de dificuldade posta sobre o "aprender matemática". A resposta de A25, ilustrada na Figura 2, evidencia esse fator.

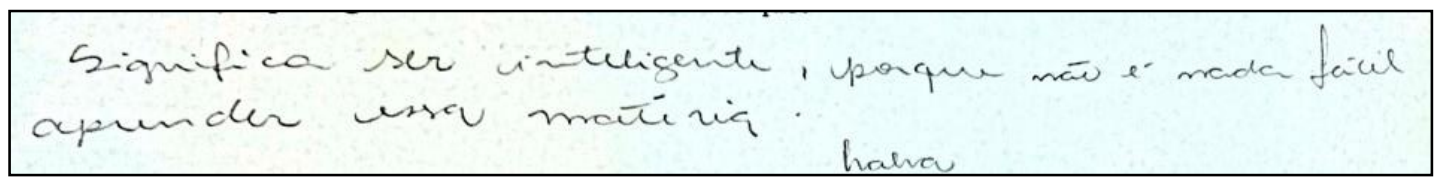

Figura 2 - Resposta do aluno A25, correspondente à primeira questão Fonte: dados da pesquisa.

Por fim, a última categoria da primeira questão enfatiza o conhecimento sobre o cotidiano e sua importância na concepção do saber matemática, de modo que em sua maioria, as respostas foram voltadas para atividades que fazem parte da vida dos alunos.

O aluno A22 assim se manifesta: "saber matemática consiste no fato de fazer cálculos para a passagem de ônibus e realizar a contagem de objetos; para outros ela está em tudo, desde o ângulo formado pelo movimento da boca ao falarmos, na natureza e até na evolução da tecnologia, destacando que a matemática é essencial em nossas vidas".

O interessante é o fato de que a pesquisa de Ferreira (2009) evidenciou que os professores também, em sua maioria, apresentam visões de matemática similares às encontradas nesse estudo com alunos, principalmente as relacionadas às aplicações cotidianas e às operações matemáticas. Acredita-se assim, que essa visão vem de um construto social, não importando o papel educativo do entrevistado.

Logo, corrobora-se com Ponte (1992, p.1) ao afirmar que "nossas concepções sobre matemática são influenciadas pelas experiências que nos habituamos a reconhecer como tal e pelas representações sociais dominantes."

Prosseguindo, a segunda questão investigada é sobre qual animal poderia representar a matemática e o porquê da escolha realizada. O Quadro 3 descreve as categorias elencadas para esta questão após a análise das respostas. 
Quadro 3 - Categorias correspondentes à segunda questão

\begin{tabular}{|c|c|}
\hline \multicolumn{2}{|c|}{ Questão 2: Se a matemática fosse um animal, qual ela seria? Por quê? } \\
\hline Categorias & Número de Respostas \\
\hline $\begin{array}{c}\text { Animais que remetem } \\
\text { exatidão/inteligência/sabedoria }\end{array}$ & 8 respostas \\
\hline Animais que remetem sentimentos negativos & 6 respostas \\
\hline Associações sem justificativa & 2 respostas \\
\hline $\begin{array}{c}\text { Associações que remetem ao conhecimento } \\
\text { e medo (ambos) }\end{array}$ & 12 respostas \\
\hline
\end{tabular}

Fonte: dados da pesquisa.

A primeira categoria foi intitulada animais que remetem exatidão, inteligência e sabedoria, sendo citados pelos alunos, o leão, a anta, a formiga, a águia, a mamãe pato e o chimpanzé.

As características citadas, que fazem referência a esses animais, são adjetivos como a inteligência, a persistência para vencer desafios, a exatidão em suas ações, a responsabilidade para descobrir o certo e o errado, e o simbolismo do conhecimento e da sabedoria, o que pode representar todas as disciplinas.

Ao observar a variedade de respostas e os adjetivos admitidos a cada animal, verifica-se que a ideia geral apresentada se trata de possíveis qualidades para se aprender matemática, bem como as respectivas dificuldades.

Já a segunda categoria trata dos animais que remetem a sentimentos negativos. Foi possível identificar novamente a ideia de dificuldade no aprendizado de matemática. Os animais destacados foram a baleia, o passarinho, o elefante, a cobra, o leão e a aranha.

As associações com estes animais se deram devido a matemática, para alguns, ser muito pesada, maçante, "causando estragos por onde passa" (A18). Outro adjetivo citado nesta categoria foi o fato de muitos gostarem da matemática, mas a acharem difícil de se compreender.

A terceira categoria foi composta por uma única resposta, em que o pássaro foi citado, sem justificativa alguma. Por fim, a quarta categoria destacou a interseção entre o sentimento do medo e do conhecimento. Nessa, surgiram respostas como o leão, o gato, a borboleta, o cachorro, o cavalo e o unicórnio. 
O leão e o gato foram os animais mais citados. Apontam uma visão interessante pois, para os alunos, mesmo que estes animais sejam ferozes, difíceis de lidar e possuírem garras, quando dominados podem se tornar dóceis e tranquilos, assim como a matemática.

Dispuseram para os demais animais características como o enfrentamento das dificuldades para se chegar ao sucesso, ou seja, a compreensão da disciplina; também a justificativa da disciplina ser de outro mundo, e por isso, o unicórnio.

Ainda, o cachorro e o cavalo foram citados pelo fato de poderem assustar algumas pessoas e oferecerem perigo, de modo que seja preciso dominá-los. Esse mesmo sentimento se refere à matemática.

Seguindo, no questionamento de número três, os alunos foram indagados a responder sobre qual animal a matemática nunca seria comparada e o porquê, o que acarretou novamente em respostas diversas. As categorias criadas para essa questão estão apresentadas no Quadro 4.

Quadro 4 - Categorias correspondentes à terceira questão

\begin{tabular}{|c|c|}
\hline \multicolumn{2}{|c|}{ Questão 3: Qual animal a matemática nunca seria? Por quê? } \\
\hline Categorias & $\begin{array}{c}\text { Número de } \\
\text { Respostas }\end{array}$ \\
\hline Animais que remetem sentimento negativo & 11 respostas \\
\hline Animais sem justificativa/Sem resposta & 3 respostas \\
\hline Associações que remetem ao conhecimento e ao medo (ambos) & 2 respostas \\
\hline Associações que remetem à aplicabilidade da matemática & 3 respostas \\
\hline Animais que remetem inteligência & 9 respostas \\
\hline
\end{tabular}

Fonte: dados da pesquisa.

Para a categoria animais que remetem a sentimento negativo, os citados foram o bicho-preguiça por três vezes, o gato por duas vezes, o cachorro, o unicórnio, o passarinho e o mosquito.

As características presentes nesta categoria foram baseadas em ações e emoções como, por exemplo, o bicho-preguiça foi citado por não ser um animal desafiador e nem um pouco esforçado, ações estas necessárias para se aprender matemática.

O segundo animal mais citado foi o gato e, para este, os adjetivos consistiram em falta de concentração e seriedade. Os demais animais elencados englobaram 
características peculiares, de modo que surgiram frases como "a matemática não poderia ser um unicórnio, ele é fofo e amado" (A18), ou ainda, "ela nunca seria um urso, pois ele é meigo, e a matemática é assustadora" (A25).

Ou seja, observa-se que os animais citados eram, em sua grande maioria, fofos, meigos, bonitinhos e fáceis de lidar e, por isso, não poderiam representar esse componente curricular.

Com relação à segunda categoria, dois alunos citaram os animais, porém sem justificativa alguma. $\mathrm{O}$ aluno A4 citou a galinha e o aluno A6, um passarinho. Um outro aluno acabou por não responder a questão proposta.

A terceira categoria fazia menção ao conhecimento e ao medo, na mesma resposta. Somente dois animais foram citados: a lagarta e o cachorro. A citação da lagarta faz analogia à caminhada quando se quer aprender matemática, pois ela, no início de sua vida, se caracteriza por ser um pouco estranha, mas quando vira borboleta as pessoas mudam sua visão sobre ela. Já o cachorro, foi citado por ser um animal previsível, que só de olhar já se sabe qual será sua reação.

A próxima categoria tratou dos animais que remetiam à aplicabilidade da matemática. Foram citados o rato, o dinossauro e a barata. $\mathrm{O}$ rato foi citado por fugir das enrascadas, resolvendo seus problemas. Já o dinossauro por estar extinto, e a matemática estar sempre presente em nossas vidas. Por fim, a barata destacou-se por somente assustar e não servir para nada, conforme ressaltou o aluno A27.

A última categoria desta questão voltou-se para animais que remetem inteligência, sendo citados, o camarão, a lesma, a barata, o panda, o hamster, a galinha, a minhoca, a borboleta e o mosquito Aedes Aegypti.

Alguns animais foram citados devido ao fato de não apresentarem grau de inteligência elevado, por isso, a matemática nunca seria representada por eles, outros por serem preguiçosos e não apresentarem disposição para os desafios.

O aluno A9 optou por falar na analogia da matemática com o mosquito Aedes Aegypti, conforme ilustra a Figura 3. 


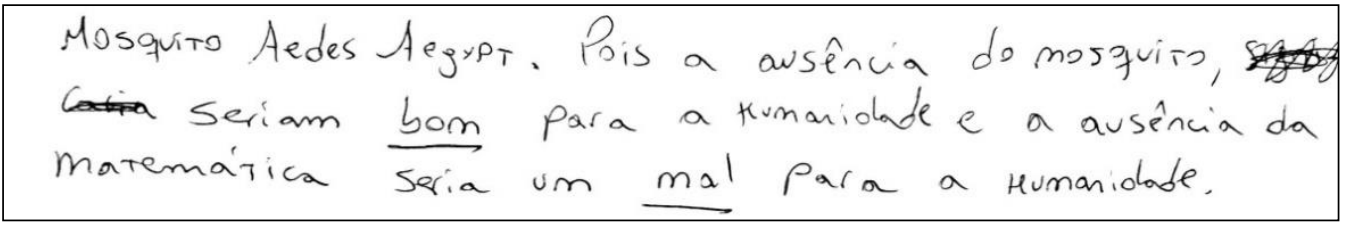

Figura 3 - Resposta do aluno A9, correspondente a terceira questão

Fonte: dados da pesquisa.

Ainda, destaca-se a resposta do aluno A11, em que diz que a matemática é uma disciplina insensível, o que é ilustrado na Figura 4.

$$
\text { Ima pormiga, porque elas } 5 \overline{00} \text { sensivers e a matemaitica noo. }
$$

Figura 4 - Resposta do aluno A11 correspondente à terceira questão

Fonte: dados da pesquisa.

Assim, pode-se observar dois tipos de pensamentos sobre a matemática: enquanto alguns a adoram, outros não possuem tanta afinidade e a encaram como sendo impossível de aprender.

Ao realizar um comparativo com outros estudos, como o de Ferreira (2009), realizado com professores, percebe-se que algumas visões são bastante similares, remetendo na maioria dos casos, às relações entre o conhecimento e o medo. Entretanto, os professores se preocupam também com a evolução da matemática enquanto ciência, citando que ela não seria, por exemplo, um bicho preguiça, que não avança. Talvez, a escola tenha que trabalhar um pouco mais esse olhar, para que os estudantes também compreendam essa visão da disciplina enquanto ciência.

Por fim, chega-se à questão de número quatro, em que foi solicitado aos alunos para demonstrar seu pensamento e sentimento sobre a matemática por meio de um desenho. Constatou-se que os alunos buscaram diferentes maneiras de expressar seu pensamento de forma ilustrativa. O Quadro 5 mostra as categorias elaboradas para esta questão. 
Gabriel de Oliveira Soares, Andressa Franco Vargas e José Carlos Pinto Leivas

Percepções e sentimentos de alunos do ensino médio em relação à matemática

Quadro 5 - Categorias correspondentes à terceira questão

\begin{tabular}{|c|c|}
\hline \multicolumn{2}{|c|}{ Questão 4: Faça um desenho que expresse seu pensamento e sentimento em à matemática: } \\
\hline Categorias & Número de respostas \\
\hline Sem resposta & 1 respostas \\
\hline Sentimentos positivos & 6 respostas \\
\hline Sentimentos negativos & 10 respostas \\
\hline Sentimentos positivos e negativos & 6 respostas \\
\hline Associações com conceitos & 3 respostas \\
\hline Aplicações do cotidiano & 2 respostas \\
\hline
\end{tabular}

Fonte: dados da pesquisa.

Para uma melhor explicação, foram destacados desenhos referentes a cada categoria. A primeira delas se refere a um único sujeito que não expressou seu pensamento em forma de desenho, logo, deixou a questão em branco.

A segunda categoria faz referência aos sentimentos positivos sobre a matemática. A Figura 5 traz os desenhos dos alunos A6 (a) e A12 (b) e seus sentimentos sobre a referida disciplina.

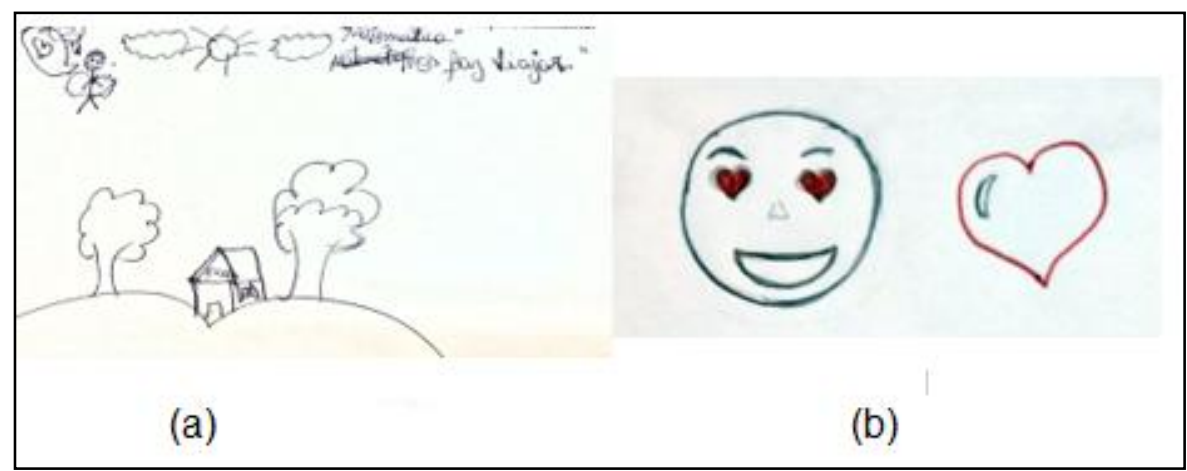

Figura 5 - Respostas dos alunos A6(a) e A12(b) correspondentes à quarta questão.

Fonte: dados da pesquisa.

Quando se separou os desenhos para a terceira categoria, observou-se que ela dispunha do maior número de respostas. Logo, concluiu-se que os alunos ainda têm medo e dificuldades para aprender matemática e que isto está interiorizado. Pode-se observar a 
Figura 6, que ilustra os desenhos dos alunos A17 e A24, nos quais suas reações são de desentendimentos e desespero sobre a matemática.

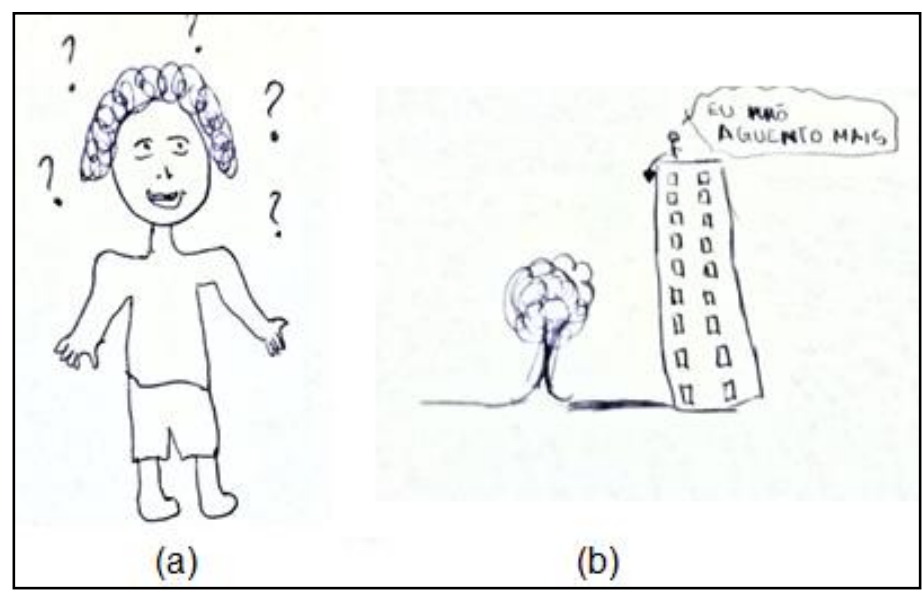

Figura 6 - Respostas dos alunos A17(a) e A24(b), correspondentes à quarta questão.

Fonte: dados da pesquisa.

A próxima categoria estava relacionada com ambos os sentimentos, os positivos e os negativos. Nela destacam-se dois desenhos que simbolizam a desmistificação da matemática como uma disciplina incompreensível, pois é verificável uma evolução após o entendimento dela, o que fica evidente na representação feita pelos alunos. A Figura 7 ilustra a resposta de dois estudantes alocados nessa categoria.

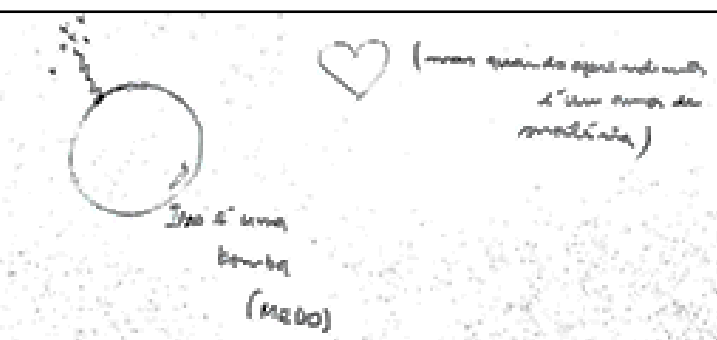

(a)

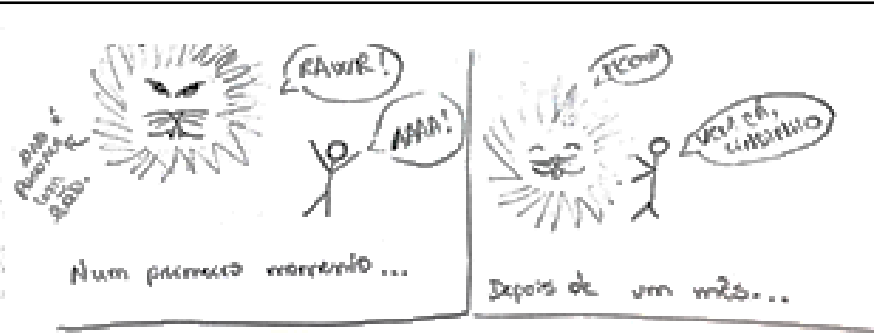

(b)

Figura 7 - Respostas dos alunos A7(a) e A25(b), correspondentes a quarta questão.

Fonte: dados da pesquisa.

Na primeira imagem a bomba se transforma num coração e, na segunda, o leão furioso se torna um gatinho dócil, o que evidencia a evolução da aprendizagem em matemática e um amadurecimento desses alunos. 
A penúltima categoria trata da associação dos desenhos a conceitos matemáticos conhecidos pelos alunos o que acarretou o montante de três respostas. Decidimos destacar duas representações, as realizadas pelos alunos A14 e A15, em que eles abordam de forma diferente os conteúdos vindos em suas memórias. O primeiro representa, de forma equivocada, o conceito de fração, já o segundo expressa que para ele a matemática pode ser representada na forma de um cubo, como se vê na Figura 8.

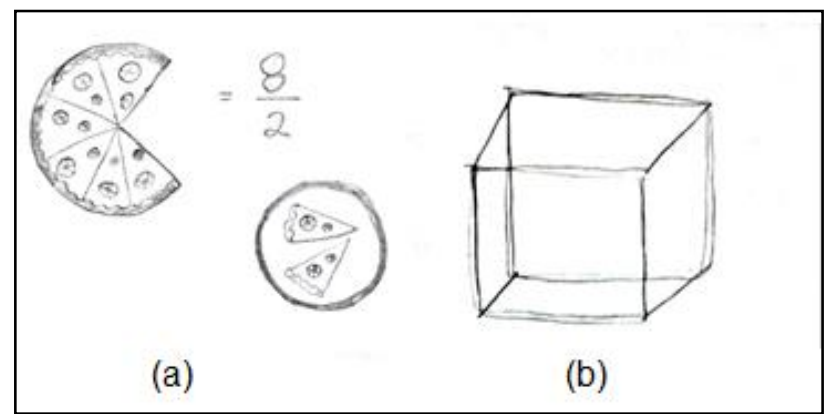

Figura 8 - Respostas dos alunos A14(a) e A15(b), correspondentes à quarta questão.

Fonte: dados da pesquisa.

Ressaltamos, ainda, que a primeira figura, disposta do lado esquerdo, demonstra o conteúdo frações, porém o aluno A14 representa de forma errada a divisão de sua pizza, elegendo como seu numerador o número total de fatias e no seu denominador as fatias cortadas, quando o correto deveria ser o contrário. Já o aluno A15 desenha apenas um cubo, o que pode ter sido algo presente em sua memória ao estudar o tópico de geometria espacial.

A última categoria enfatizou a aplicação da matemática em atividades do cotidiano, contabilizando duas respostas. Em uma delas, interpretou-se que o aluno A4 representou um pensador grego refletindo sobre as medidas de uma construção. Já o aluno A9 desenhou moedas e notas de papel, simbolizando que a matemática para ela pode ser expressa na forma de economia, finanças. A Figura 9 representa os desenhos feitos por estes estudantes. 


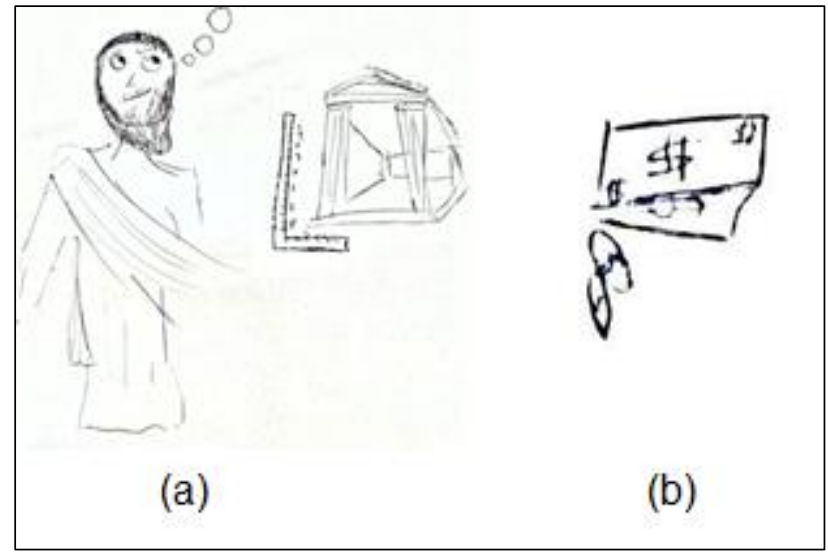

Figura 9 - Respostas dos alunos A13(a) e A14(b), correspondentes à quarta questão.

Fonte: dados da Pesquisa

Deste modo, a partir da fala de um dos alunos, "que a matemática nos permite viajar" (A14), pode-se entender que a matemática nos permite circular por vários mundos, pela natureza, pela economia, pela engenharia, pela agricultura, pela saúde, pela educação, etc. Sendo assim, acredita-se que o papel dos professores, além de ensinar os conteúdos formais da área, seja também proporcionar ao aluno momentos em que possa imaginar viajar e construir novos conhecimentos tendo como impulso principal suas respectivas vivências.

Ainda, pode-se observar nas falas que muitos alunos têm receio sobre a disciplina e destacam a dificuldade para aprender e gostar da mesma, o que pode ser um dos motivos para o baixo índice de aprovações em matemática em nosso país. Corrobora-se com o apontado por Belardi Neto e Martins (2015),

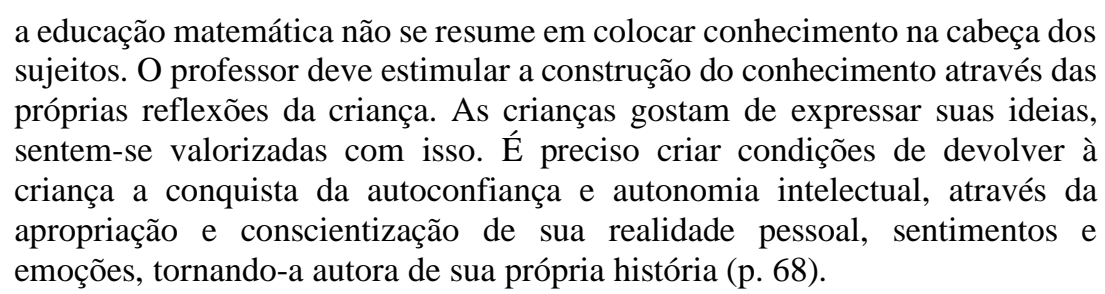

Talvez seja necessário motivar uma mudança de pensamento num primeiro momento, para que, com isso, se possa chegar num aprimoramento da qualidade do ensino e da aprendizagem de matemática. 


\section{Considerações finais}

Esse trabalho teve o objetivo de investigar percepções e sentimentos de alunos do Ensino Médio em relação à matemática expressas por uma turma desse nível de escolaridade de uma instituição de ensino pública de um município da região central do estado do Rio Grande do Sul.

Após a análise das respostas, foi possível observar as crenças dos alunos sobre a matemática e concluir que muitos possuem uma visão um pouco negativa sobre ela, de modo que a têm como algo que exige bastante conhecimento e causa medo. Corroborando com as ideias de Chacón (2003), pode-se questionar se não seria este um dos problemas iniciais que impedem a aprendizagem na disciplina de matemática. Obviamente, não se pode concluir de forma efetiva, por este estudo, uma resposta a tal questionamento. Entretanto, o presente estudo mostrou que as percepções e sentimentos sobre a matemática, enquanto disciplina, apresentaram números significativos quanto à negatividade.

Outro ponto que pode ser destacado, após as análises, é a visão dos alunos sobre a importância e a presença da matemática em atividades que fazem parte de suas vidas e na natureza. Esse reconhecimento pode auxiliar no entendimento da importância de aprender matemática na escola e em outros ambientes.

Logo, pode-se concluir que as percepções e sentimentos destacados pelos alunos se mostraram alternativa para descobrir um caminho para mudança de pensamento em se tratando do ensino de matemática. Para tal, é necessário que haja, também, uma mudança na postura do professor ao ensinar, pois, ao buscar compreender esses aspectos emocionais dos estudantes em relação à disciplina, ele pode elaborar estratégias para romper barreiras, colocando o aluno em uma posição de pré-disposição a aprender e participar. Afinal, é preciso ouvi-los, dialogar e buscar compreender como tornar tanto o ensino quanto a aprendizagem mais eficazes.

\section{Agradecimentos}

O presente trabalho foi realizado com apoio da Coordenação de Aperfeiçoamento de Pessoal de Nível Superior - Brasil (CAPES) - Código de Financiamento 001. 


\section{Referências}

BELARDI NETO, V. L. L.; MARTINS, M. A. V. Emoções e sentimentos: Uma análise de sua inferência na aprendizagem da Matemática. In: COLÓQUIO DE PESQUISA QUALITATIVA EM MOTRICIDADE HUMANA, 6., 2015. Anais... Valdivia, Chile: São Carlos: SPQMH, 2015. p. 60-69.

CHACÓN, I. M. G. Matemática emocional: os afetos na aprendizagem matemática. Porto Alegre: Artmed, 2003.

CHAPMAN, O. Researching teaching: qualitative techniques. Caderno de Pesquisa em Educação, v. 12, n. 23, jan/jun. 2006. p. 105-135.

CURY, H. N. Concepções e Crenças dos Professores de Matemática: pesquisas realizadas e significado dos termos utilizados. Bolema, v. 12, n. 13, 1999. p. 29-43.

FERREIRA, M. L. Álgebra: Como as crenças dos professores influenciam na aprendizagem dos alunos. 151f. 2009. Dissertação (Mestrado em Ensino de Matemática) - Universidade Federal do Rio de Janeiro, Rio de Janeiro, 2009.

FONSECA, M. C. F. R. O caráter evocativo da matemática e suas possibilidades educativas. Zetetiké, v. 7, n. 1, 1999. p. 29-37.

GARNICA, A. V. N. Um ensaio sobre as concepções de professores de Matemática: possibilidades metodológicas e um exercício de pesquisa. Educação e Pesquisa, v. 34, n.3, set./dez. 2008. p. 495-510.

LORENZATO, S. Para aprender matemática. 3. ed. Campinas: Autores Associados, 2010 .

LUDKE, M.; ANDRÉ, M. Pesquisa em educação: abordagens qualitativas. São Paulo: EPU, 1986.

MACEDO, L. Ensaios construtivistas. São Paulo: Casa do Psicólogo, 1994.

NACARATO, A. M.; PASSOS, C. L. B.; CARVALHO, D. L. Os graduandos em pedagogia e suas filosofias pessoais frente à matemática e seu ensino. Zetetiké, v. 12, n. 21, jan./jun. 2004. p. 9-34.

PACHECO, M. B.; ANDREIS, G. S. L. Causas das dificuldades de aprendizagem em Matemática: percepção de professores e estudantes do $3^{\circ}$ ano do Ensino Médio. Revista Princípia, v. 38, 2018. p.105-119.

PIENDA, J. A.; NÚÑEZ, J. C.; ÁLVAREZ, L.; GONZÁLEZ-CASTRO, P.; SOLER, E.; GONZÁLEZ-PUMARIEGA, S.; ROCES, C.; BERNARDO; RODRIGUES, L. S. Actitudes hacia el aprendizaje de las matemáticas y rendimiento académico. In: CONGRESSO GALAICO-PORTUGUÊS DE PSICOPEDAGOGIA, 8., 2005.

Anais...Braga: Universidade do Minho, 2005. p. 14-16. 
PONTE, J. C. P. Concepções dos professores de matemática e processos de formação. 1992. Disponível em: <http://www.educ.fc.ul.pt/docentes/jponte/docs-pt/92Ponte(Ericeira).pdf>. Acesso em: 10 mar. 2020.

PONTE, J. C. P. O ensino da matemática em Portugal: Uma prioridade educativa?. 2002. Disponível em: < http://educ.fc.ul.pt/docentes/jponte/docs-pt/02-Ponte(cne).pdf $>$. Acesso em: 10 mar. 2020.

SANCHEZ, J. N. G. Dificuldades de aprendizagem e intervenção psicopedagógica. Porto Alegre: Artmed, 2004.

SILVA, T. L. C.; SANTOS-WAGNER, V. M. P. Concepções, memórias e escolha profissional de futuros professores de Matemática. In: ENCONTRO NACIONAL DE EDUCAÇÃO MATEMÁTICA, 11., 2013. Anais... Curitiba: UFPR, 2013. p. 1-15.

SILVEIRA, A. R. M. A Dificuldade da Matemática no Dizer do Aluno: ressonância de sentido de um discurso. Educ. Real, v. 36, n. 3, 2011. p. 761-779.

TALL, D. How humans learn to think mathematically. Cambridge: Cambridge University Press, 2013. 